\title{
Tobacco Counter-Marketing And Policy In A University Setting: The Use Of Experiential Learning Projects To Bring About Change
}

\author{
Deanna D. Mader, (E-mail: maderd@marshall.edu), Marshall University \\ J.D. Harrah, (E-mail: harrah@marshall.edu), Marshall University \\ James M. See, (E-mail: unavailable), Marshall University
}

\begin{abstract}
Four million deaths from tobacco-related illness and disease occurred worldwide in 1999 and that number is likely to increase to 10 million by the 2030s. Each year, 430,000 Americans die from such causes. Tobacco use among young people has remained constant, and in some cases, increased even though information regarding the hazards of tobacco consumption has received growing attention over the last decade, The present paper discusses the process and results of an undergraduate experiential learning project designed to 1) educate college students about the hazards of tobacco consumption, 2) prevent or reduce college students' consumption of tobacco products through counter-marketing efforts, and 3) assess and change current tobacco related policies on campus. The two-semester project incorporated both fall and spring Promotion Management and Health Care Management classes and involved cooperation from the College of Business, the Medical School, and the Office of Student Affairs.
\end{abstract}

\subsection{Introduction}

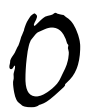

ne would have to be a hermit for the last decade not to have been made aware of the hazards of tobacco use. Even with a general awareness, however, the figures and facts are staggering. It has been reported that an estimated four million deaths occurred worldwide from tobacco in 1999 and that the annual number of deaths is likely to rise to 10 million by the 2030s (Glantz, 1999; Peto \& Lopez, 2000). About 450 million cumulative tobacco-related deaths will have occurred by 2050, mostly in low-income countries (Peto \& Lopez, 2000).

The health care information for the United States, a developed nation, is no better. Tobacco-related illness and disease kill 430,000 Americans each year (Glantz, 1999). For one of the tobacco cousins, cancer, the 2001 estimate for new cases was 1,268,000 (Cancer - Estimated New Cases and Deaths, 2001; Cancer - Estimated New Cases, 2001, and Sites, 2001). Of that figure, approximately 170,000 new cases of lung cancer were estimated for 2001; up from 13,500 cases in the 1980-1982 time period. The estimated health care costs due to tobacco related illnesses and disease is $\$ 75$ billion (MCGoldrick, 2002). Figures such as these, while catastrophic, are not surprising given the content of tobacco and tobacco products. Cigarette smoke, for example, contains nearly 4,000 chemicals including poisons and carcinogens (Glantz, 1999; McCowan, 2002).

Readers with comments or questions are encouraged to contact the authors via email.

Although there has been a decline in tobacco use in some parts of the world overall, an increase has been noted in lower income nations and in young people ((Jha, Ranson, Nguyen, \& Yach, 2002). The Centers for Disease 
Control (Youth Tobacco Use and Exposure is a Global Problem, 2002) reported a recent study that found cigarette smoking among students in the United States was $17.7 \%$, whereas the global median was $13.9 \%$ for the same age group. Smoking went down in the U.S. overall from 1985 to 1998, however smoking went up for white males between the ages of 18 to 24 years (Current Cigarette Smoking: 1985 to 1998, 2001). Some research indicates that the availability of cigarettes by Internet vendors may be compounding the problem (Ribisl, Kim, \& Williams, 2002). Smoking is not the only tobacco problem among young people, however. About 1 out of 3 high school students try some form of tobacco, with about 18\% using spit tobacco (Hagen, 2002

Clearly, the means to reduce tobacco-related illnesses and disease, and also to reduce related health care costs, is to prevent the use of tobacco products. Although tobacco use is declining for adults, most tobacco users, worldwide, began use as teens or young adults (Jha \& Chaloupka, 1999). The goal then should be to educate young people about the hazards of tobacco use, and in fact, some groups and organizations are doing just that (Farrelly, Healton, Davis, \& Messeri, 2002). However, most of these approaches target the 12 to 17 year olds. The hazards need to be communicated, as well, to the difficult to reach 18 to 24 year old target market.

Peer communication approaches utilizing experiential learning projects may provide one avenue for reaching this age group. As universities shift from being places of providing instruction to places responsible for producing learning (Barr \& Tagg, 1995; Saunders, 1997) and as faculty take on the role of learning facilitators as opposed to teachers (Johnston \& Usher, 19997; Miller, 1997), experiential leaning projects have gained increased attention and use. Experiential learning projects provide numerous benefits to students regarding skill acquisition and learning (de los Santos \& Jensen, 1985; Dommeyer, 1986; Gaidis \& Andrews, 1990; Henke, Locander, Mentzer, \& Nastas, 1988; Mader \& Mader, 2000; Mercer, 1996; Richardson \& Ginter, 1998) and a means for community service (Daudeliln, 1996; Easterling \& Rudell, 1997; Saunders, 1997).

\subsection{Project Purpose And Procedure}

The purpose of this enterprise was to implement an experiential learning project designed to 1) educate college students about the hazards of tobacco consumption, 2) prevent or reduce college students' consumption of tobacco products through counter-marketing efforts, and 3) assess and promote change in current tobacco related policies on campus. Students in two courses within the college of business at a mid-sized comprehensive state university in the mid-east participated as peer change agents in the project. Specifically, the two-semester design incorporated both fall and spring Promotion Management and Health Care Management classes. Pre-and postproject survey questions were included as part of a larger campus survey conducted by the Office of Student Affairs. Funding was provided by a state grant and involved cooperation between the College of Business, the Medical School, and the Office of Student Affairs at the institution. The following sections describe the project and its impact.

\subsection{Counter-Marketing}

During fall 2001, the students in the Promotion Management class were divided into small groups and assigned the task of developing a full promotion plan as part of a larger grant-funded pilot project. The students were informed of several key points:

- $\quad$ groups would work on a competitive basis acting in an agency "shootout" process;

- $\quad$ the primary goal of the promotion plan and implementation would be to bring about awareness of the hazards of tobacco use and to encourage tobacco prevention and cessation among members of the target audience;

- $\quad$ the primary target audience would be 18-24 year olds at the university;

- $\quad$ the total promotion budget would be $\$ 4000$; 
- $\quad$ promotion plans would need to be realistic and operational;

- $\quad$ the best ideas from the promotion plans would be implemented by the spring 2002 Promotion Management class

With these guidelines as the foundation, the seven student groups each developed a complete promotion plan and each plan was presented formally to the class. In addition, a panel consisting of university faculty rank ordered the projects and certificates were presented to members of the top three projects.

During spring 2002, the students of Promotion Management were assigned the tasks of 1) examine all seven fall 2001 projects and, as a group, select the best ideas for implementation; 2) implement the ideas as one promotion project in order to bring about awareness of the hazards of tobacco use and to encourage tobacco cessation among 18-24 year olds at the university; 3) stay within the $\$ 4000$ promotion budget; and 4) generate a report of the process. The class was divided into departments (advertising, sales promotion, public relations, and logistics) and the professor served as the project coordinator. The following sections describe the results of the promotion plan implementation.

\subsection{Promotion Implementation}

The final promotion plan and its implementation included each of the following promotion mix elements: sales promotion, advertising, and publication relations. Specific action plans within each element were chosen based upon the desired goals, target market, and expense. Media selections were necessarily conservative due to the $\$ 4000.00$ promotion budget.

\subsection{Sales Promotion}

Event

The primary form of sales promotion used in implementation was a campus event. The event titled, "Smokeout 2002," was held from 11:00am until 1:00pm in late spring semester on the university's student center plaza. Since it was determined that smoking is the number one tobacco product of choice among members of the target audience (as determined by an earlier campus study), it was decided that smoking also would be the primary focus of the event. However, it should be noted that educational materials and one-on-one discussions included all forms of tobacco use.

\section{4-Hour Tobacco-Free Pledge}

Tables were placed on the plaza on the high-pedestrian traffic side of the student center - a major walkway to classroom buildings and dormitories, and where students typically congregate during the lunch periods. Students working at the event tables encouraged passing students to complete and sign the pledge to be tobacco free for 24 hours. The pledge form included the statement, "I understand that using any tobacco product is detrimental to my health," as well as the campaign educational original logo (character with the statement "Don't Cough Up A Lung"). Completing the pledge form entered the student into a drawing for prizes donated by area businesses. Each person who completed a pledge form also received one of the educational flyers.

\section{Educational Flyer}

Flyers detailing facts regarding tobacco use were distributed to all students at the event. Each flyer contained information in areas such as health hazards, out-of-pocket costs for tobacco purchases, research results, and issues of self-perception.

\section{T-Shirts}


The first 50 students who completed the pledge form received a free T-shirt with the logo (cartoon-like character in dismay having just coughed up his lungs) and "Don't Cough Up A Lung! Smokeout 2002" printed on the front. Approximately the next $150 \mathrm{~T}$-shirts were released only if the person put out their cigarette/cigar, spit out their chew, or gave us their unused cigarettes/cigars, spit tobacco or lighters and completed the pledge form. This process was completed both at the plaza event tables and by class members (with garbage bags in hand) who approached tobacco users at the most popular smoking sites on campus. To this end, it could be said that personal selling was also used because the class members approached tobacco users and provided them with educational materials and an opportunity to complete the pledge form.

The T-shirts provided a popular and lasting medium for present and continued communication regarding the hazards of tobacco use. The graphic educational logo and message were designed for this specific target market.

Food

Free food was provided to all persons who demonstrated an interest in taking the pledge and/or picking up educational materials at the plaza. The food was donated by a popular local radio station and included pizza, hotdogs, sub sandwiches, and fresh vegetables.

\section{Live Remote}

Finally, persons in the target market were drawn to the plaza site by a live remote broadcast by a popular DJ at the above mentioned radio station. The boom box at her table was tuned to the station for continuous music and, at eight different times in the two-hour block, the station broke away to her live broadcast from the site.

\subsection{Advertising}

\section{"Facts" Educational Flyers}

Educational flyers in six bright colors were used to target students on campus approximately two weeks prior to the event (the week before Spring Break) and again the week of the event (the week following Spring Break). Flyers were placed in classrooms and common areas in the most often used classroom buildings on campus in addition to the student center and dormitories. Each flyer contained one of twelve facts about the hazards of tobacco use. In total, 250 flyers were distributed two weeks prior to the event, and another 500 were distributed three days prior to the event.

\section{Radio Ads}

In an earlier study of this university's students, conducted by the spring 2001 Promotion Management students, respondents were asked to rank-order the local radio stations in order of preference. Therefore, it was determined that the most popular radio station should be the radio station of choice for the tobacco cessation ads and awareness of the event. In addition, radio would provide the added benefits of popularity among the target market (e.g. radio/rock music), availability (home, car, office, portable), repetition, coverage of the market, and relatively low cost. An advertising consultant at the radio station was contacted and a contract was drawn up for consideration. In addition, she stated that the station would assist us with food donations for the event. The contract was reviewed by the Promotion Management students and approved.

Radio ads, produced by the station, ran 11 times per day for the three days preceding the event and an additional 15 times the day of the event. The event was also included in the radio station's on-air information updates and as "live liners" by the DJs 10 times respectively during the same four-day period.

\section{Event Flyers}


Flyers using the educational campaign logo announcing the event were also used on campus. Distribution followed the same process as the educational fact flyers, but with fewer in number. In total, 75 event flyers were distributed two weeks before the event and 150 event flyers were distributed three days prior to the event.

\section{Educational Pamphlet}

An educational pamphlet titled, "50 Things You Should Know About Tobacco," was distributed inside the campus newspaper the day of the event. The pamphlet, produced by a national publishing house, was inserted in 3000 issues of that day's edition.

\subsection{Public Relations}

\section{Articles in the University's Newspaper}

An article of approximately 10 column inches appeared in the university's newspaper the day of the event. The article, titled, "Students Challenge Smokers to 'Butt Out' for 24 Hours," began on the front page and continued on page three. A second follow-up article of similar size titled, "Marketing Class Designs Smoke-Out Challenge to Learn, Promote Quitting," appeared on page two in the campus newspaper five days later. Both articles provided information about the hazards of tobacco use, incidence of tobacco use, and details of the peer counter-marketing project.

\section{Local Station and University Radio Station Public Service Announcements}

The previously mentioned local radio station aired Public Service Announcements (PSAs) for the event three days before and the day of the event. PSAs also were aired on the campus radio station the entire week prior to and including the event.

\section{Banner}

A 3' X 5' banner was produced and hung on the balcony of the student center prior to and during the event. The banner incorporated the logo, title of the event, and the university affiliation. The names of prize donors were highlighted at the bottom of the banner.

\subsection{Policy Change}

Tobacco-related policies on campus and in the local community focused specifically on smoking. Therefore, the fall semester Health Care Management class, divided into groups of three to four students, thoroughly researched the respective smoking policies and related health care information. Based on their findings, the students critiqued the policies and prepared documents detailing their work. Each project paper included recommendations for university smoking policy change.

As in the case of the promotion plans, a panel consisting of university faculty rank ordered the policy projects and certificates were presented to members of the top three groups. The student group who received the top award met with the university's Vice President for Executive Affairs and General Counsel to discuss their recommendations.

Students in the spring Health Care Management class were divided into teams and assigned the task of researching the available tobacco-related health care research as well as the present and proposed local and university smoking policies. At the end of the term, teams held debates on the issue.

University and community smoking policy proposals received attention in the campus and local media. Articles and live-remote radio broadcasts at the event included information regarding the policy part of the project. 


\subsection{Impact}

Pre-project surveys were administered to 943 undergraduates enrolled in randomly selected classes in various departments across the university. Post-project surveys were administered to 691 undergraduates in a like fashion. Data collection occurred in early fall semester and again during the two weeks following the countermarketing event. Survey results and anecdotal information regarding the project's impact were very positive, thereby supporting the use of peer communications and experiential learning projects in targeting the 18-24 year old target market. The following sections detail the results of the projects:

- $\quad$ Survey results indicated that $25.4 \%$ of the students surveyed had read at least one of the counter-marketing "Fact" flyers posted on campus. Anecdotally, numerous students, faculty, and staff reported (unsolicited) having seen the "Fact" flyers posted around campus. It is worth noting that these mentions were not simply observations of colorful flyers, but accurate recall of the "Facts." Persons commented, for example, "I didn't know that tobacco use was linked to poor academic performance," or "I was surprised to find out that tobacco use can lead to premature baldness."

- $\quad$ The event was overwhelming successful. Over 400 persons signed the pledge to be tobacco-free for 24 hours. Post-event survey results showed that of the 25 (3.6\%) respondents who signed the 24-hour tobacco-free pledge, 21 (84\%) were still tobacco-free.

- Nearly 100 tobacco items were "turned in" during the event by members of the target market in addition to those who were willing to put out their cigarette/cigar or spit out their chew. Each of these persons also signed the pledge to be tobacco-free for 24 hours.

- All persons attending the event or who were approached to "turn in" their tobacco products were given educational materials regarding the hazards of tobacco use whether or not they were willing to complete the pledge form. Approximately $12 \%$ of the students surveyed attended the counter-marketing event.

- Nearly $14 \%$ of the students surveyed stated they had read the pamphlet, "50 Things You Should Know About Tobacco," inserted in the campus newspaper. Anecdotally, only 5-10 educational pamphlets were found on the floor at each of the distribution sites for the newspaper. To the casual observer, this may not sound significant. However, the floor is typically covered in discarded materials when pamphlets/flyers are distributed in that manner. It would seem from this observation that, in fact, persons were at least taking the pamphlet away with them to examine it.

- $\quad$ The T-shirts were very popular among members of the target market. The educational logo and message were graphic and succinct and. definitely appealed to this age group. We ran out of T-shirts prior to the end of the event. The counter-marketing T-shirts can still be seen worn by students around campus and at their places of employment in the community.

- Publicity was excellent in print and on air with the two radio stations. Again using anecdotal information, many persons commented they had seen the articles or heard the live spots/announcements. Of the students surveyed in the spring, $56 \%$ stated they were aware of the university's policy on tobacco use. This was up from nearly $48 \%$ in the fall.

- $\quad$ Policy change proposals, presentation, and debates helped to bring attention to the university's smoking policy issue. The Faculty Senate brought the discussion forward and developed a new smoking policy to help alleviate the problems.

This work was funded by a grant from the West Virginia Bureau for Public Health - Tobacco Prevention Program. 


\section{References}

1. Barr, R.B. \& Tagg, J. (1995). "From teaching to learning: A new paradigm for undergraduate education." Change, 27, 13-25.

2. Centers for Disease Control, "Youth tobacco use and exposure is a global problem (2002)." http://www.cdc.gov/tobacco/global/GYTS/speeches\&pr/youth_tobaccoPR.htm.

3. Daudelin, M.W. (1996). "Learning from experience through reflection." Organizational Dynamics, 24, 36-48.

4. De los Santos, G. \& Jensen, T.D. (1985). "Client sponsored projects: bridging the gap between theory and practice." Journal of Marketing Education, 7, 45-50.

5. Dommeyer, C.J. (1986). "A comparison of the individual proposal and the team project in the marketing research course." Journal of Marketing Education, 8, 30-38.

6. Easterling, D. \& Rudell, F. (1997). "Rationale, benefits, and methods of service-learning in marketing education." Journal of Education for Business, 73, 58-61.

7. Farrelly, M., Healton, C.G., Davis, K.C., Messeri, Pl. "Getting to the truth: Evaluating national tobacco countermarketing campaigns." American Journal of Public Health, 92, 901-907.

8. Gaidis, W.C. \& Andrews, J.C. (1990). "Management of experiential learning projects in marketing coursework." Journal of Marketing Education, 12, 49-60.

9. Glantz, S.A. (1999). Tobacco: Biology and politics, Second Edition. Waco, Texas: Health EDCO. (1999).

10. Hagen, E. (2002). "Don't even start.” West Virginia Bureau for Public Health Division of Tobacco Prevention Annual Conference, Charleston, WV, September 9-10.

11. Henke, J.W., Locander, W.B., Mentzer, J.T. \& Nastas, G. III (1988). "Teaching techniques for the new marketing instructor: Bringing the business world into the classroom." Journal of Marketing Education, 10, 110.

12. Jha, P. \& Chaloupka, F (1999). "Curbing the epidemic: Governments and the economics of tobacco control." Washington, D.C.: The World Bank.

13. Jha, P., Ranson, M.K., Nguyen, S.N., \& Yach, D. (2002). "Estimates of global and regional smoking prevalence in 1995, by age and sex." American Journal of Public Health, 92, 1002-1006.

14. Johnston, R. \& Usher, R. (1997). "De-theorising experience: Adult learning in contemporary social practices." Studies in the Education of Adults, 29, 137-153.

15. Mader, D.D. \& Mader, F.H. (2000). "The live case: A tool for teaching critical thinking in undergraduate business education." Ethics \& Critical Thinking Quarterly Journal, 2, 1-15.

16. McCowan, R.J. (2002). "Cardiovascular health and its implications for tobacco prevention." West Virginia Bureau for Public Health Division of Tobacco Prevention Annual Conference, Charleston, WV, September 9-10.

17. McGoldrick, D. (2002). "Tobacco control in the new millennium: Sustaining successes and achieving new ones." West Virginia Bureau for Public Health Division of Tobacco Prevention Annual Conference, Charleston, WV, September 9-10.

18. Mercer, G.I. (1996). "The global citizenship MBA orientation program: Action learning at the University of Michigan business school." Journal of Business Ethics, 15, 111-120.

19. Miller, M.A. (1997). "Good, Mr. Chips?" Change, 29, 4.

20. Peto, R. \& Lopez A.D. (2000). "The future worldwide health effects of current smoking patterns." In E.C. Koop, C.E. Pearson, \& P.M Schwartz (Eds.), Global health in the $21^{\text {st }}$ century (pp. 154-161). New York: Jossey-Bass.

21. Ribisl, K.M, Kim, A.E., \& Williams, R.S. (2002). "Are the sales practices of Internet cigarette vendors good enough to prevent sales to minors?" American Journal of Public Health, 92, 940-941.

22. Richardson, W.D. \& Ginter, P.M. (1998). "Using living cases to teach the strategic planning process." Journal of Education for Business, 73, 269-273.

23. Saunders, P.M (1997). "Experiential learning, cases, and simulations in business communication." Business Communication Quarterly, 60, 97-114.

24. U.S. Census Bureau. "Cancer - Estimated new cases, 2001, and sites (2001)." Statistical Abstract of the United States. Washington, D.C.:

25. U.S. Census Bureau. "Cancer - Estimated new cases and deaths (2001)." Statistical Abstract of the United States. Washington, D.C.:

26. U.S. Census Bureau. "Current cigarette smoking: 1985 to 1998 (2001)." Statistical Abstract of the United States. Washington, D.C.:

Notes 